\title{
Shelf-scale mapping of sound production by fishes in the eastern Gulf of Mexico, using autonomous glider technology
}

\author{
Carrie C. Wall ${ }^{1, *}$, Chad Lembke ${ }^{2}$, David A. Mann ${ }^{1}$ \\ ${ }^{1}$ College of Marine Science and ${ }^{2}$ Center for Ocean Technology, University of South Florida, St. Petersburg, Florida 33701, USA
}

\begin{abstract}
Autonomous gliders are a relatively new technology for studying oceanography over large time and space scales. We integrated a hydrophone into the aft cowling of a glider and used it in a $1 \mathrm{wk}$, shelf-scale deployment on the West Florida Shelf to detect and map fish sounds in the ocean over a large spatial scale. In addition to red grouper and toadfish sounds, at least 3 unknown biological sounds suspected to be produced by fish were identified through manual analysis of the acoustic files. The biogeography of these fishes was identified by mapping the occurrence of sounds along the glider track. Sounds produced by red grouper and toadfish were detected throughout the day predominately in bottom depths $>40 \mathrm{~m}$. Conversely, the 3 unknown biological sounds were detected exclusively at night over varying bottom depths. Glider technology provides a reliable and relatively inexpensive method to collect acoustic and environmental data over large spatial scales while maintaining a high rate of successful retrieval.
\end{abstract}

KEY WORDS: Passive acoustics - Sound production - Autonomous gliders - Gulf of Mexico · Epinephelus morio Opsanus spp.

Resale or republication not permitted without written consent of the publisher

\section{INTRODUCTION}

Sound has long been recognized as an important means of animal communication (Aristotle 1910). In the ocean, the range of acoustic communication often exceeds the range of visibility (Urick 1983, Hawkins 1993, Bass \& Clark 2003). Sound production in fishes is used for communication and has been shown to be associated with courtship, spawning, parental, aggressive and territorial behavior (Lobel et al. 2010). Most fish sounds are species-specific and repetitive, which enables passive acoustic recordings of sound production to be used to identify their distribution and behavior.

Passive acoustic monitoring (PAM) systems can record large amounts of acoustic data. These systems are often moored in a specific area for days to years, recording sounds from biological, physical (e.g. noise generated from wave action) and anthropogenic (e.g. vessel traffic) sources (Urick 1983, Mellinger et al. 2007, Locascio \& Mann 2008, Luczkovich et al. 2008, Dudzinski et al. 2009). PAM systems collect data in remote locations under potentially unsafe seas throughout a $24 \mathrm{~h}$ period providing large datasets that are unobtainable using observer-based methods (Rountree et al. 2006). Since sound is associated with reproduction in many species, an important application of PAM is to determine when and where reproductive activities occur for fish and marine mammals (Mann \& Lobel 1995, Lobel 2002, Gannon 2008, Van Parijs et al. 2009, Lobel et al. 2010).

Sound alone cannot paint the full picture of biogeography. Knowledge of the ocean environment is necessary to fully understand animal behavior and distribution. Thus, platforms containing environmental sensors can be used to record data to relate patterns in sound production to oceanographic conditions (Baumgartner \& Fratantoni 2008, Mann \& 
Grothues 2008). The suite of environmental and optical sensors in autonomous ocean gliders provides a 3-dimensional view of physical and biological processes over time and space as the glider moves through the water column (Webb et al. 2001, Schofield et al. 2007, Castelao et al. 2008). Simultaneous collection of sound and environmental data can fill the gap left by PAM systems between an acoustic signal and the environment in which that sound was produced. To this end, several studies have recently evaluated passive acoustic glider data collected from integrated hydrophones (Moore et al. 2007, Baumgartner \& Fratantoni 2008, Haun et al. 2008, Ferguson et al. 2010, Matsumoto et al. 2011). Their research has focused largely on marine mammal acoustics or ambient noise.

The purpose of the present study was to detect and map fish sounds in the ocean over a large spatial scale - in this case an oceanic shelf - using glider technology. For this study a hydrophone was integrated into the aft cowling of a Slocum electric underwater glider (Teledyne Webb Research), and used to record sound and other oceanographic parameters such as temperature, salinity, and chlorophyll concentration, during a deployment off west-central Florida.

\section{MATERIALS AND METHODS}

Slocum gliders are buoyancy-driven electric autonomous underwater vehicles, $1.8 \mathrm{~m}$ in length and shaped like a winged torpedo (Webb et al. 2001, Schofield et al. 2007). They can traverse over $600 \mathrm{~km}$ using a single set of alkaline batteries and contain sensors that measure temperature, salinity, depth averaged currents (i.e. currents averaged vertically from near the surface to near the bottom), surface currents, fluorescence, and apparent and inherent optical properties (Schofield et al. 2007). In the present study, these measurements were taken approximately 15 times a minute as the glider ascended and descended through the water column roughly 330 times a day, depending on water depth. In addition to this suite of sensors, we integrated a hydrophone that extended $10 \mathrm{~cm}$ from the aft endcap within the waterflooded aft cowling of the glider. No part of the hydrophone extended outside of the main glider body.

The glider's digital acoustic recording system, Digital SpectroGram Recorder (DSG; Loggerhead Instruments), recorded sound for $25 \mathrm{~s}$ every $5 \mathrm{~min}$ at a sample rate of $70000 \mathrm{~Hz}$. This duty cycle optimized the collection of acoustic data for the allotted 16 GB SD card storage space. The DSG is a low- power acoustic recorder controlled by script files on the SD card in concert with the on-board real-time clock. The clock, which is synced to the clock on board the glider's computer, is highly accurate with time-compensated drift. The DSG file system is an advanced data file structure that stores embedded time stamps with the raw data allowing each file to remain time-aligned with GMT and with the glider data.

Forward propulsion in the glider is created by varying the vehicle buoyancy. The wings enable forward movement as buoyancy changes, causing the glider to move downward when it is denser than the water and upward when less dense, creating sawtooth-like profiles through the water column. The absence of a drive motor and propellers minimizes mechanical noise produced by the glider. Efforts were made prior to deployment to reduce electronic noise by including dual capacitive filtering $(1500 \mu \mathrm{F}$ and $1 \mu \mathrm{F}$ ) on the power supply coming from the glider's battery.

The glider was deployed on the West Florida Shelf on July 14, 2009. The mission started west of the mouth of Tampa Bay in $25 \mathrm{~m}$ water depth, continued westward to approximately $50 \mathrm{~m}$ water depth, and then returned to the start location where it was retrieved on July 21, 2009 (Fig. 1). During this mission, 1989 acoustic files were recorded over the $135 \mathrm{~km}$ track. Each acoustic recording is represented as a file encompassing a $25 \mathrm{~s}$ period of time. Identifiable sounds were reported as a percentage of occurrences in all of the files since the recordings were discontinuous and the location of the source and detection range of the glider was unknown. On average, the glider moved approximately 75 to $85 \mathrm{~m}$ between acoustic recordings. Fig. 2 demonstrates the approximate spatial distribution of the acoustic samples during the deepest portion of the deployment. This plot of the glider's horizontal and vertical progression was calculated using the horizontal $(0.273 \pm$ $0.026 \mathrm{~m} \mathrm{~s}^{-1}$ [mean $\left.\left.\pm \mathrm{SD}\right]\right)$, vertical ascent $(0.112 \pm$ $0.030)$, and descent $(0.160 \pm 0.035)$ speeds averaged over the entire deployment. Profiles and sample spacing in other portions were assumed to be similar, though the spacing tends to be larger in deeper water, where the glider generally moves faster, and slower in shallower water.

Metadata collected throughout the deployment included glider depth in the water column, bottom depth, GMT time stamp, roll, pitch and heading. Latitude and longitude were collected when the glider was at the surface. The position of the glider when not at the surface was estimated from the surface lat- 


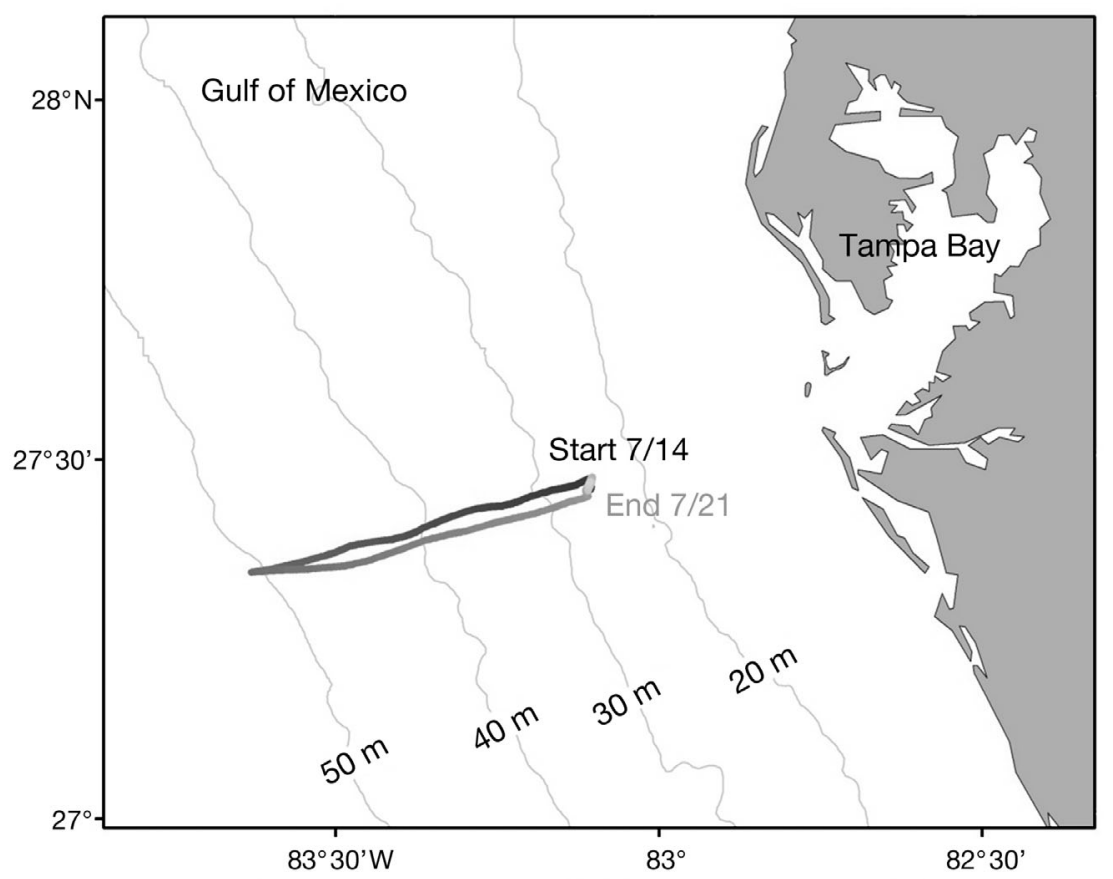

Fig. 1. Position data from a glider mission on the West Florida Shelf in the eastern Gulf of Mexico from July 14-21, 2011, during which time acoustic data were collected. Grey contours are bathymetric depth

\section{RESULTS}

Snapping shrimp from the family Alpheidae were frequently recorded by the glider, and may act as an indicator of the presence of hard bottom. Red grouper Epinephelus morio and toadfishes Opsanus spp. were among the most frequent fish sounds identified in the files. Based on location and slight differences between the calls, it is suspected the toadfish species was leopard toadfish $O$. pardus, as opposed to the inshore gulf toadfish $O$. beta (Fig. 3). The fundamental frequency and call duration for Opsanus recordings in the present study were (mean $\pm \mathrm{SE}) 190 \pm 0 \mathrm{~Hz}$ and $2.34 \pm 0.36 \mathrm{~s}$, respectively $(\mathrm{n}=10)$. This is in comparison to a fundamental frequency of 350 $\mathrm{Hz}$ and call duration of $1.23 \pm 0.22 \mathrm{~s}$ for O. beta (Tavolga 1958, Thorson \& Fine 2002). Furthermore, initial grunts were not present in these toadfish recordings, unlike $O$. beta.

itude and longitude coordinates using linear interpolation and a 10-point moving average.

Fish sounds were identified manually because automated detection methods were hampered by the presence of noise from the gliders' altimeter, pump, rudder and at-surface iridium satellite link. Sounds from known and unknown sources were mapped using the interpolated positions and acoustic file time stamp to determine spatial and temporal ranges. Temperature, salinity and chlorophyll concentration data were compared to the sounds identified in the acoustic recordings, the time of the recording, and the bottom depth when the sound was recorded. Spectrograms were generated from 2048 point Hanning windowed fast Fourier transforms (FFT) with $50 \%$ overlap. Analyses were completed using MATLAB (Mathworks) and ESRI (Environmental Systems Research Institute) ArcGIS 10 software.
Three additional suspected fish sounds were also common. The first unknown sound included a 200 to the '6 kHz sound') (Fig. 4a). This sound appeared continuously between sunset and sunrise ('night') and ranged from 5.9 to $6.4 \mathrm{kHz}$, with the dominant frequency at $6 \mathrm{kHz}$. The second unknown sound was a frequency modulating harmonic with an average peak frequency of $300 \mathrm{~Hz}$ ('300 Hz FM harmonic') (Fig. 4b). The duration of this sound was approximately $2.25 \mathrm{~s}$ with an average fundamental frequency of $150 \mathrm{~Hz}$. These calls typically contained 4 abrupt changes in frequency. Peak frequencies for frequency modulated sections were 690, 612, 531, and $399 \mathrm{~Hz}$, with a fundamental frequency of 230, 204, 177, and $133 \mathrm{~Hz}$, respectively. Harmonics reached up to $2478 \mathrm{~Hz}$. The third unknown sound was a tonal harmonic with a peak frequency of $365 \mathrm{~Hz}$ $500 \mathrm{~Hz}$ wide band around $6 \mathrm{kHz}$ (this will be termed

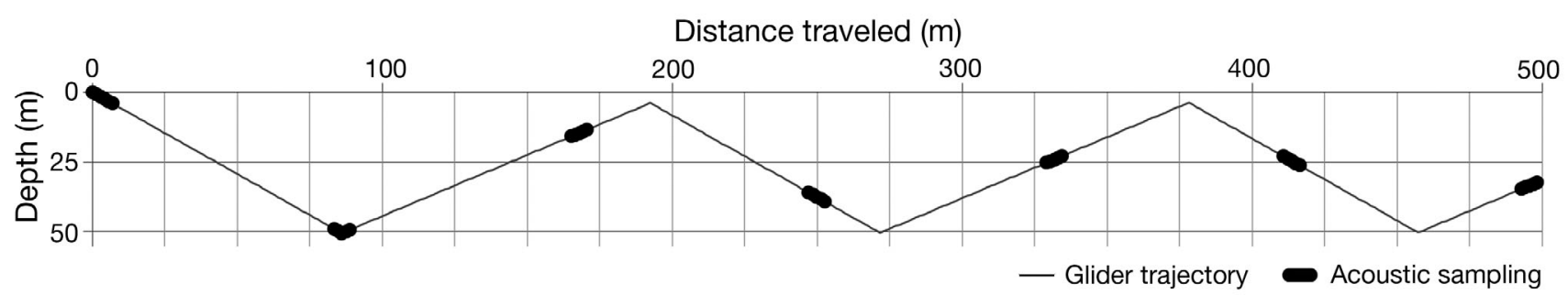

Fig. 2. Typical glider trajectory during deployment (see Fig. 1), calculated from average horizontal, ascent and descent speeds, with positions of acoustic sampling over a $30 \mathrm{~min}$ period. The acoustic data were recorded for $25 \mathrm{~s}$ every $5 \mathrm{~min}$ 

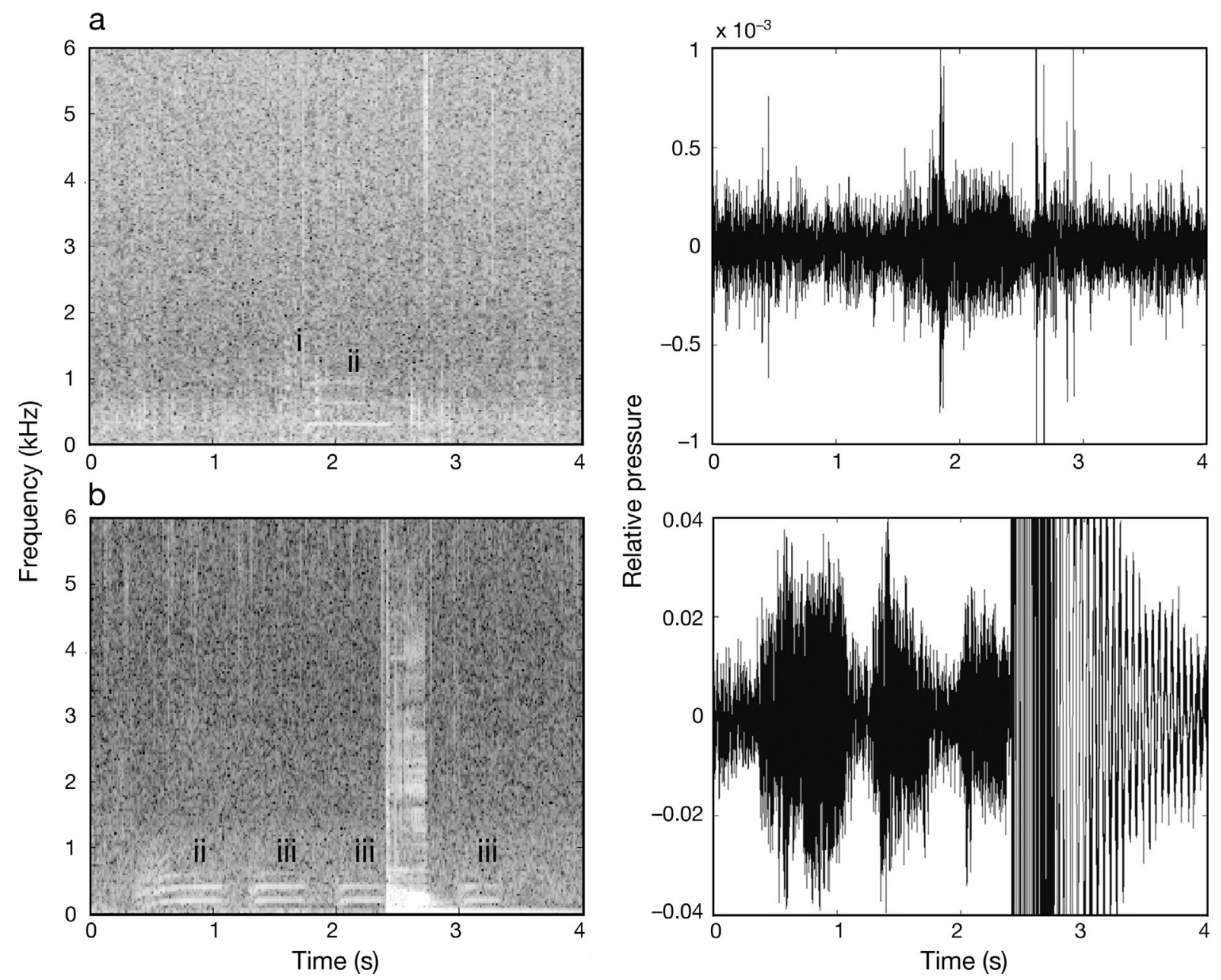

Fig. 3. Spectrogram (left) and waveform (right) of sounds from (a) Opsanus beta recorded off Tampa Bay (D. A. Mann unpubl. data) and what is suspected to be (b) $O$. pardus recorded by the glider. Grunt (i), initial tone (ii), and succeeding tones (iii) are identified. In (b), at $2.5 \mathrm{~s}$, noise from a rudder adjustment masks frequencies below $1 \mathrm{kHz}$

('365 Hz harmonic') (Fig. 4c). This sound was $0.51 \mathrm{~s}$ long ( $\mathrm{SD}=0.1, \mathrm{n}=100)$ with a $73 \mathrm{~Hz}$ fundamental frequency and the highest harmonic detected at $732 \mathrm{~Hz}$. Extensive overlap of calling was common in both $300 \mathrm{~Hz}$ FM harmonic and $365 \mathrm{~Hz}$ harmonic sounds and often made identification of individual calls difficult (Fig. 5). Whistles and echolocation produced by dolphin species, most commonly bottlenose dolphins Tursiops truncates, were also identified in the files.

Overall, the $6 \mathrm{kHz}$ sound was detected in $32 \%$ (628/1989) of the total files, the $365 \mathrm{~Hz}$ harmonic was detected in $18 \%(349 / 1989)$, red grouper were detected in $9 \%(182 / 1989)$, toadfish were detected in $8 \%(158 / 1989)$ and the $300 \mathrm{~Hz} F M$ harmonic was detected in $4 \%(87 / 1989)$. Spatial patterns in sound production for known sources (Fig. 6) and unknown sources (Fig. 7) were determined from the interpolated glider position. Red grouper (136/182; $75 \%$ ), toadfish $(158 / 158 ; 100 \%)$, and the $300 \mathrm{~Hz}$ FM har- monic $(82 / 87 ; 94 \%)$ were predominantly found where bottom depths were $>40 \mathrm{~m}$. Although they were detected throughout the glider track, the $6 \mathrm{kHz}$ sound $(330 / 628 ; 53 \%)$ and the $365 \mathrm{~Hz}$ harmonic $(234 / 349 ; 66 \%)$ were more common where the bottom depth was $<35 \mathrm{~m}$. The diurnal pattern of sound production was discerned by mapping the occurrence of sounds by time of day (Fig. 8). The $6 \mathrm{kHz}$ sound (628/628), $300 \mathrm{~Hz}$ FM harmonic (87/87), and the $365 \mathrm{~Hz}$ harmonic (347/349) sounds were detected over $99 \%$ of the time at night. Conversely, only $35 \%$ $(65 / 182)$ of the files containing red grouper sounds and $67 \%(106 / 158)$ of the files containing toadfish sounds were detected at night.

A strong thermocline and pycnocline were present near $20 \mathrm{~m}$ depth (Fig. 9a,b). Pockets of increased chlorophyll concentration were detected near the seafloor between 30 and $35 \mathrm{~m}$ depth (Fig. 9c). Temperature, salinity, and chlorophyll concentration 
a

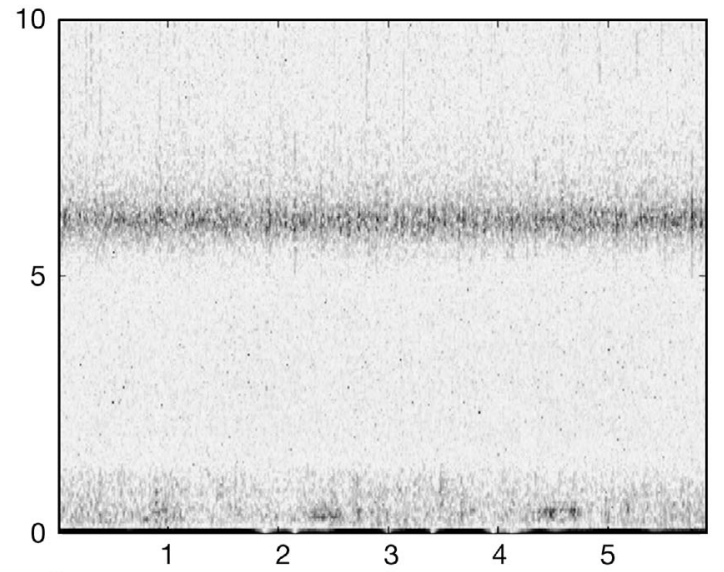

b
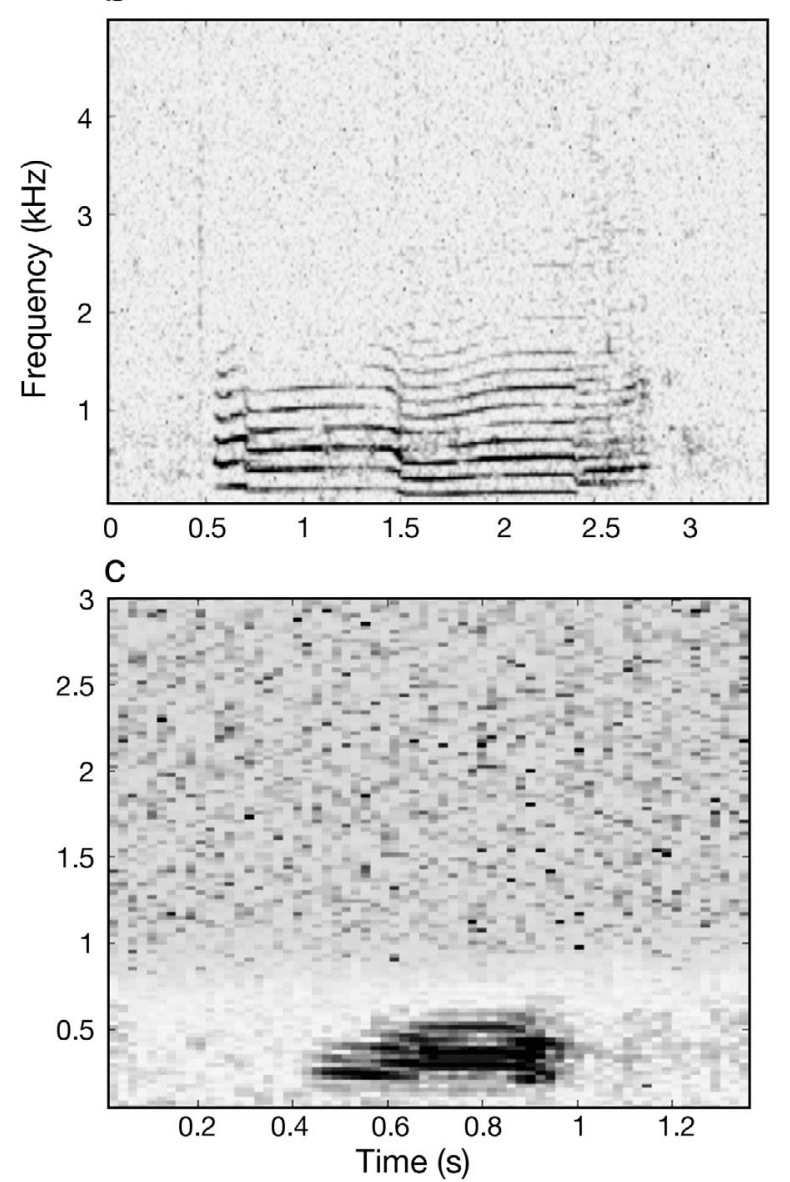
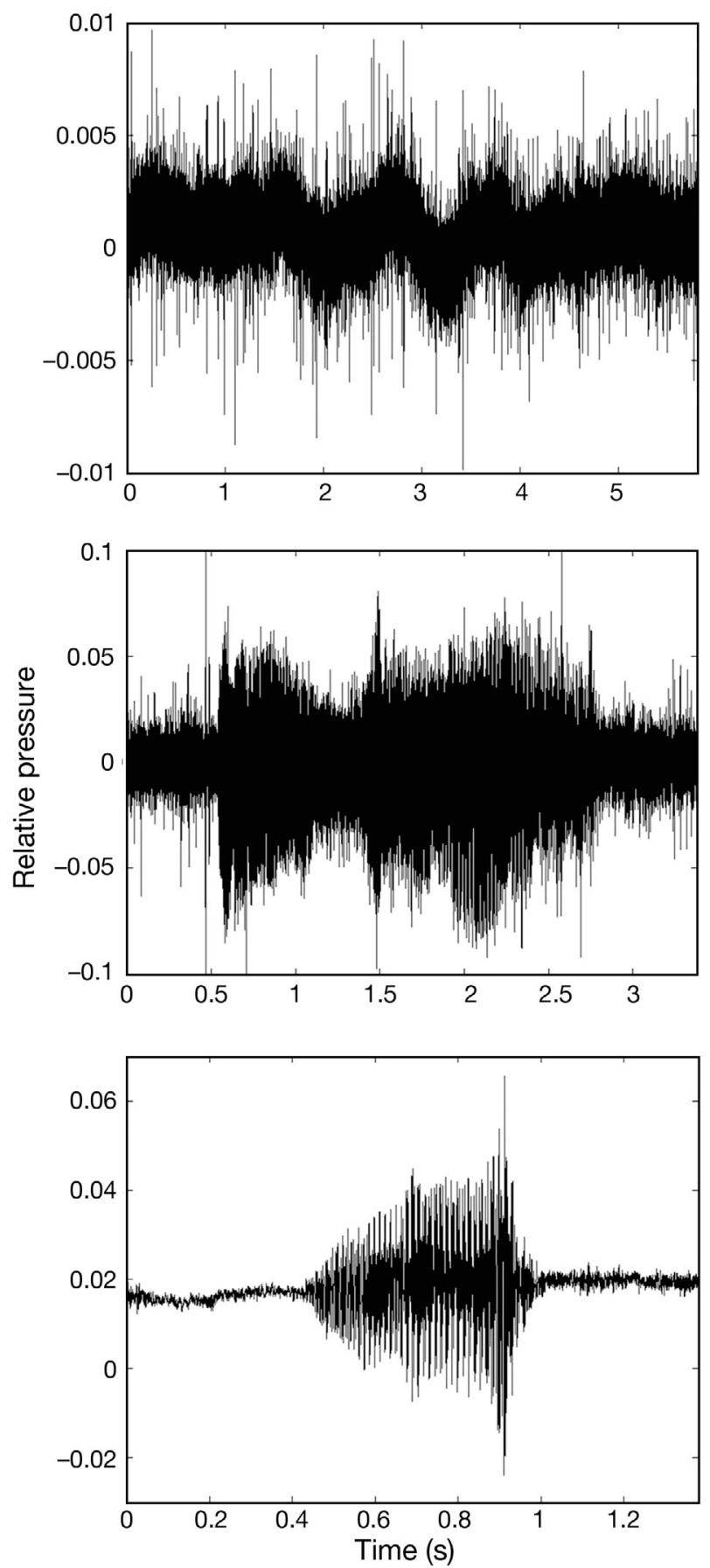

Fig. 4. Spectrogram (left) and waveform (right) of (a) $6 \mathrm{kHz}$ sound, (b) $300 \mathrm{~Hz}$ FM harmonic, and (c) $365 \mathrm{~Hz}$ harmonic. Note the differences in frequency and time scale

measurements that correspond to known and unknown sounds were compared to the associated bottom depth and hour of sound production (Table 1). Only environmental data measured when the glider was within $5 \mathrm{~m}$ of the bottom depth were incorporated into the median and SD calculations for the demersal red grouper and toadfish. The deeper bot- tom depth, decreased temperature, and increased salinity and chlorophyll concentrations reflect the conditions surrounding the expected habitat for red grouper and toadfish recorded along the glider's track. The location of the sources for the $6 \mathrm{kHz}$ Sound, $300 \mathrm{~Hz}$ FM harmonic, and $365 \mathrm{~Hz}$ harmonic are unknown. Therefore, the temperature, salinity 

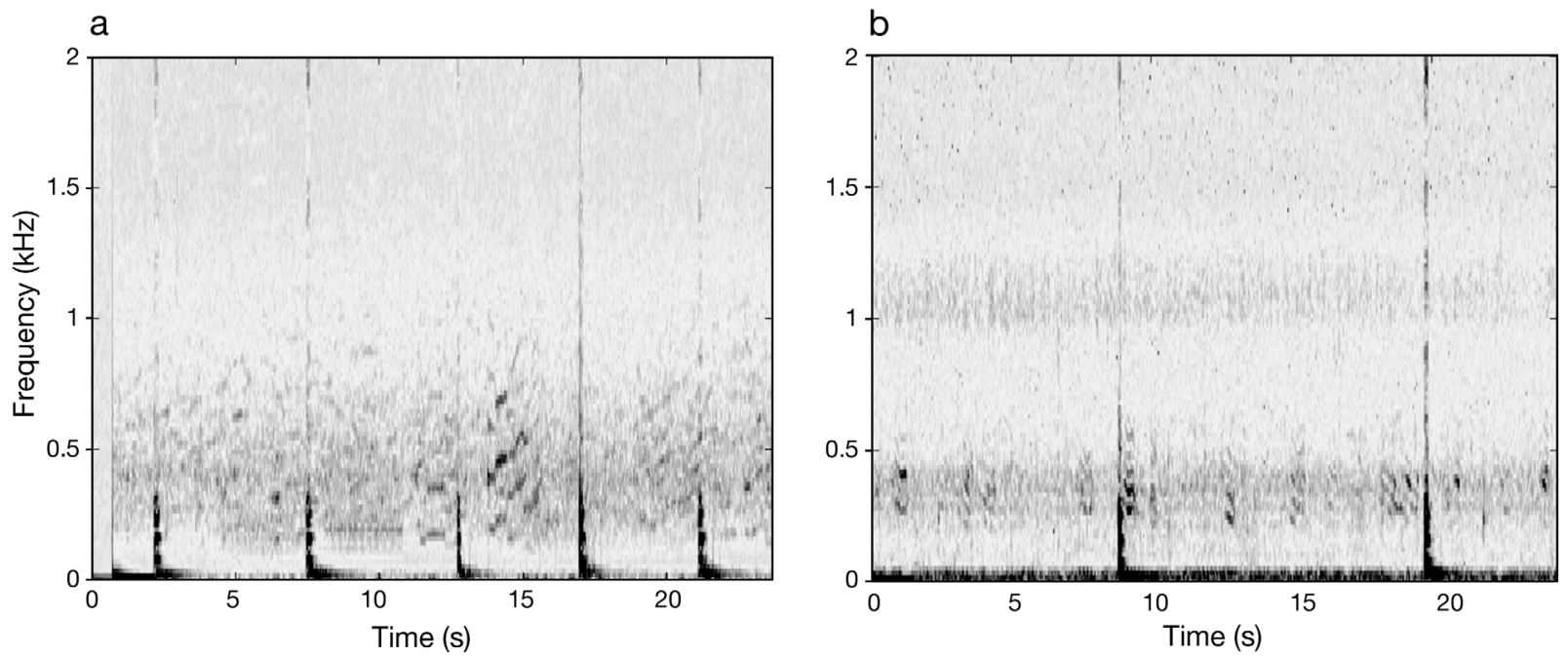

Fig. 5. Spectrographic example of overlapping calls from the (a) $300 \mathrm{~Hz}$ FM harmonic between 100 and $1000 \mathrm{~Hz}$ and (b) $365 \mathrm{~Hz}$ harmonic between 150 and $500 \mathrm{~Hz}$. Broadband noise from the glider's rudder is present every 5 to $10 \mathrm{~s}$ in the files

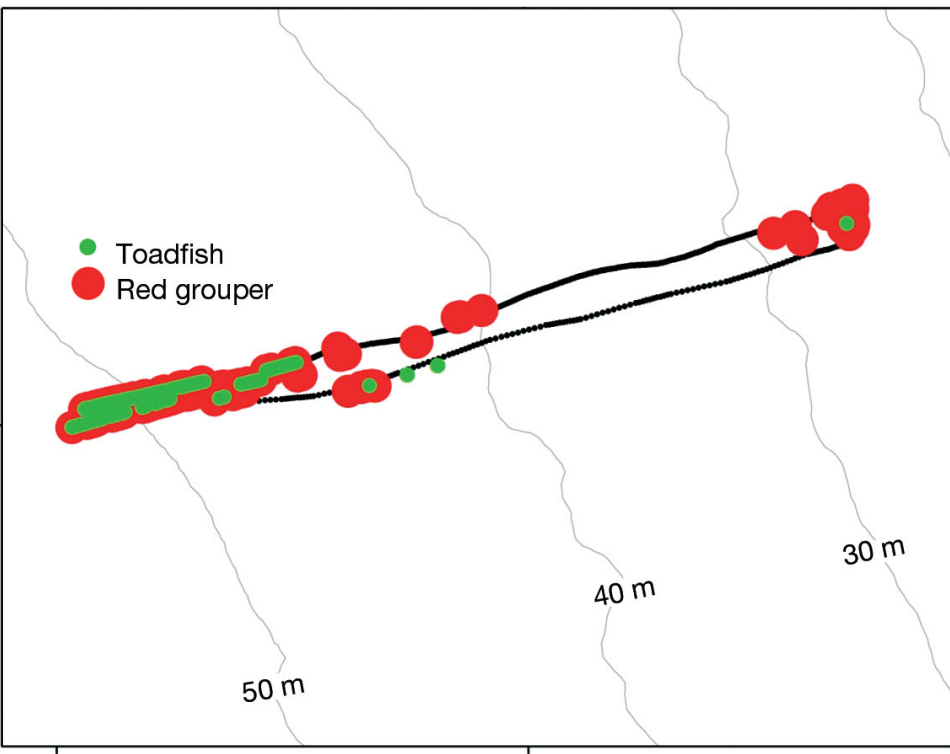

$83^{\circ} 40^{\prime} \mathrm{W}$

$83^{\circ} 20$

Fig. 6. Position along the interpolated glider track (๑) of 2 known sounds, toadfish (green circle) and red grouper (red circle), identified in the acoustic files. $\mathrm{n}=158$ and 182 , respectively

Table 1. Median and SD of bottom depth, local hour of sound production ( $24 \mathrm{~h}$ check), temperature, salinity, and chlorophyll concentration associated with known and unknown fish sounds. Only temperature, salinity and chlorophyll concentration measurements recorded when the glider was within $5 \mathrm{~m}$ of the bottom depth were calculated for red grouper $(n=30)$ and toadfish $(n=20)$

\begin{tabular}{|lcccccc|}
\hline & Depth $(\mathrm{m})$ & Hour & Temp. $\left({ }^{\circ} \mathrm{C}\right)$ & Salinity & Chl $\left(\mu \mathrm{pl}^{-1}\right)$ & $\mathrm{n}$ \\
\hline Red grouper & $48.6 \pm 8.5$ & $10 \pm 6$ & $24.6 \pm 1.7$ & $36.5 \pm 0.1$ & $0.6 \pm 0.2$ & 181 \\
Toadfish & $49.6 \pm 2.4$ & $17 \pm 9$ & $24.5 \pm 0.3$ & $36.5 \pm 0.0$ & $0.6 \pm 0.1$ & 158 \\
6 kHz sound & $32.9 \pm 6.6$ & $4 \pm 9$ & $28.9 \pm 1.5$ & $36.2 \pm 0.3$ & $0.2 \pm 1.4$ & 628 \\
300 Hz FM harmonic & $42.8 \pm 3.0$ & $5 \pm 10$ & $27.7 \pm 1.7$ & $36.3 \pm 0.2$ & $0.2 \pm 0.3$ & 87 \\
365 Hz harmonic & $32.1 \pm 4.8$ & $5 \pm 9$ & $29.1 \pm 1.2$ & $36.2 \pm 0.3$ & $0.3 \pm 1.8$ & 349 \\
\hline
\end{tabular}

and chlorophyll concentration measurements associated with these sounds were incorporated without concern for the glider's position in the water column and typically resulted in higher SDs.

\section{DISCUSSION}

A hydrophone-integrated glider was deployed successfully for $1 \mathrm{wk}$ in the eastern Gulf of Mexico in 2009, covering $135 \mathrm{~km}$. During this time, nearly 2000 acoustic files were recorded. Manual analysis of these files identified the frequent occurrence of sounds produced by red grouper and toadfish along with three unknown sources suspected to be fish (6 kHz sound, $300 \mathrm{~Hz}$ FM harmonic, $365 \mathrm{~Hz}$ harmonic).

Red grouper and toadfish produced sound throughout a $24 \mathrm{~h}$ period, mainly in depths $>40 \mathrm{~m}$. These characteristics support the finding that red grouper, who prefer deeper water, call throughout the day and night (Nelson et al. 2011). Our results also illustrate the ability of the glider's hydrophone to record demersal species (red grouper and toadfish), regardless of the glider's location in the water column, within a $50 \mathrm{~m}$ depth range. The $6 \mathrm{kHz}$ sound, the 


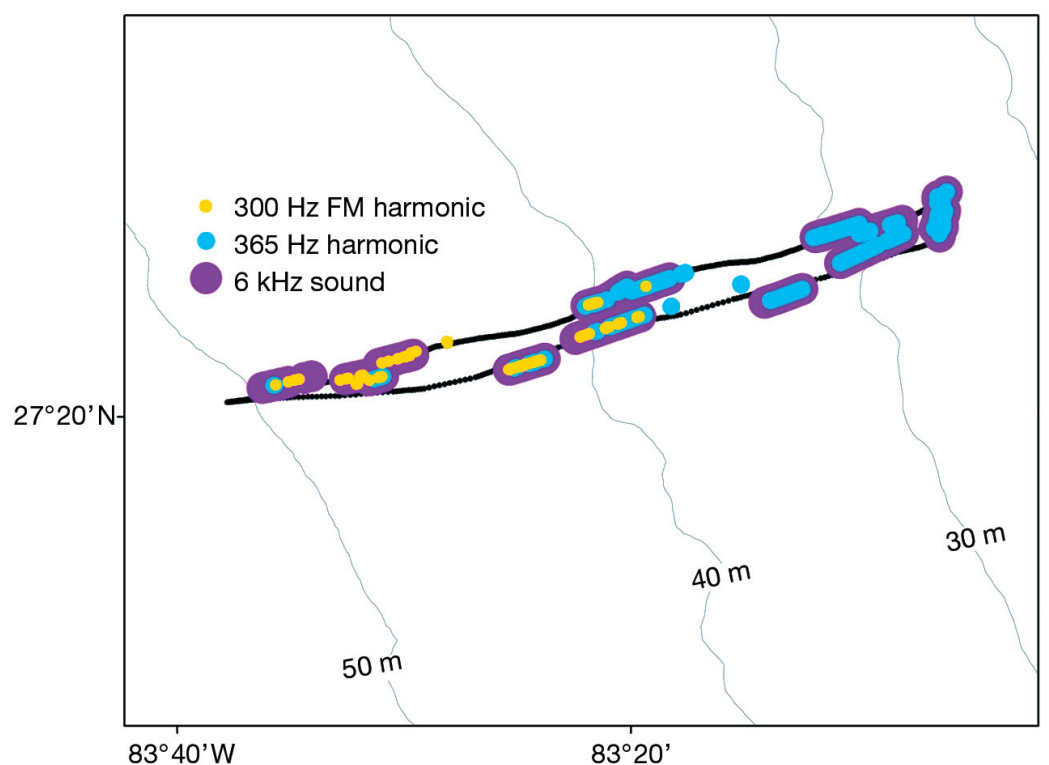

Fig. 7. Position along the interpolated glider track (๑) of 3 unknown sounds identified in the acoustic files: $300 \mathrm{~Hz}$ FM harmonic, $365 \mathrm{~Hz}$ harmonic, and $6 \mathrm{kHz}$ sound. $\mathrm{n}=87,349$, and 628 , respectively

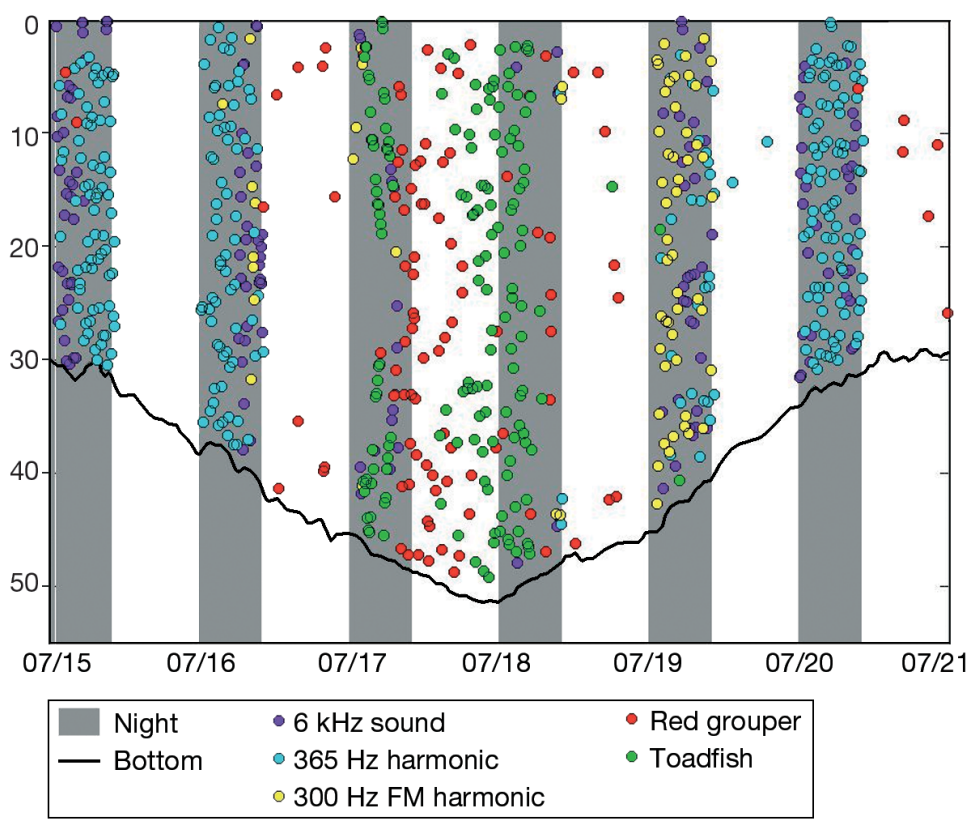

Fig. 8. Occurrence of fish sounds identified in the glider acoustic files plotted by time and depth of the glider in the water column at the date $(\mathrm{mm} / \mathrm{dd})$ of the recording. The black line indicates the bottom depth measured by the glider's altimeter and illustrates the glider's offshore and then onshore track during the mission

$300 \mathrm{~Hz}$ FM and the $365 \mathrm{~Hz}$ harmonics were only detected at night, and the $6 \mathrm{kHz}$ sound and the $300 \mathrm{~Hz}$ FM harmonic were predominately detected in depths $<40 \mathrm{~m}$. The impact of masking between 100 to $2400 \mathrm{~Hz}$ from call overlap by the $300 \mathrm{~Hz}$ FM har- monic and the $365 \mathrm{~Hz}$ harmonic is potentially significant.

The Opsanus sp. recording produced a characteristic toadfish 'boatwhistle'. However the depth range ( 25 to $50 \mathrm{~m}$ ) of the glider track and the low fundamental frequency $(190 \mathrm{~Hz})$ of the recorded sound distinguishes it from the nearshore $(<5 \mathrm{~m})$ $O$. beta and $O$. tau, which have been described extensively (Tavolga 1958, Gray \& Winn 1961, Winn 1964, Thorson \& Fine 2002, Locascio \& Mann 2008). We suspect that $O$. pardus, the offshore species of toadfish present in the Gulf of Mexico, is the source of the stereotypic toadfish calls present in the glider's acoustic recordings, although its acoustic signal has not been described. Locascio \& Mann (2008) reported nocturnal calling of $O$. beta with peaks at sunrise and sunset. Though not described in their paper, $O$. beta sound production was also observed during the day (J. Locascio pers. comm.), which is consistent with the lack of a strong diel periodicity observed in the suspected O. pardus calling.

The results from this initial work can be used to help determine the source of the 3 unknown suspected fish sounds. A preliminary analysis of families of sound-producing fishes in the Gulf of Mexico using published literature (Fish \& Mowbray 1970, Hoese \& Moore 1998) and unpublished sound recordings identified nearly 90 genera likely to make sound (C. Wall unpubl. data). Discussions with colleagues and a priori knowledge of behavior and habitat make Atlantic midshipman Porichthys plectrodon a likely candidate for the $300 \mathrm{~Hz}$ FM harmonic, which is similar to the 'grunt' call of the plainfin midshipman Porichthys notatus (Brantley \& Bass 1994, A. H. Bass pers. comm.). The documented sound production of Prionotus carolinus establishes searobin species (e.g. Blackwing searobin Prionotus rubio) as likely candidates for the $365 \mathrm{~Hz}$ harmonic (Connaughton 2004). We suspect the $6 \mathrm{kHz}$ sound is related to gas release in clupeids (e.g. Gulf menhaden Brevoortia patronus) (Nøttestad 1998, Wahlberg \& Westerberg 2003, Wilson et al. 2004, Doksæeter et al. 2009, Knudsen et al. 2009). Based on the nocturnal characteristics and depth preferences identified in the study, and the reduced list of candidates, efforts can be honed with 

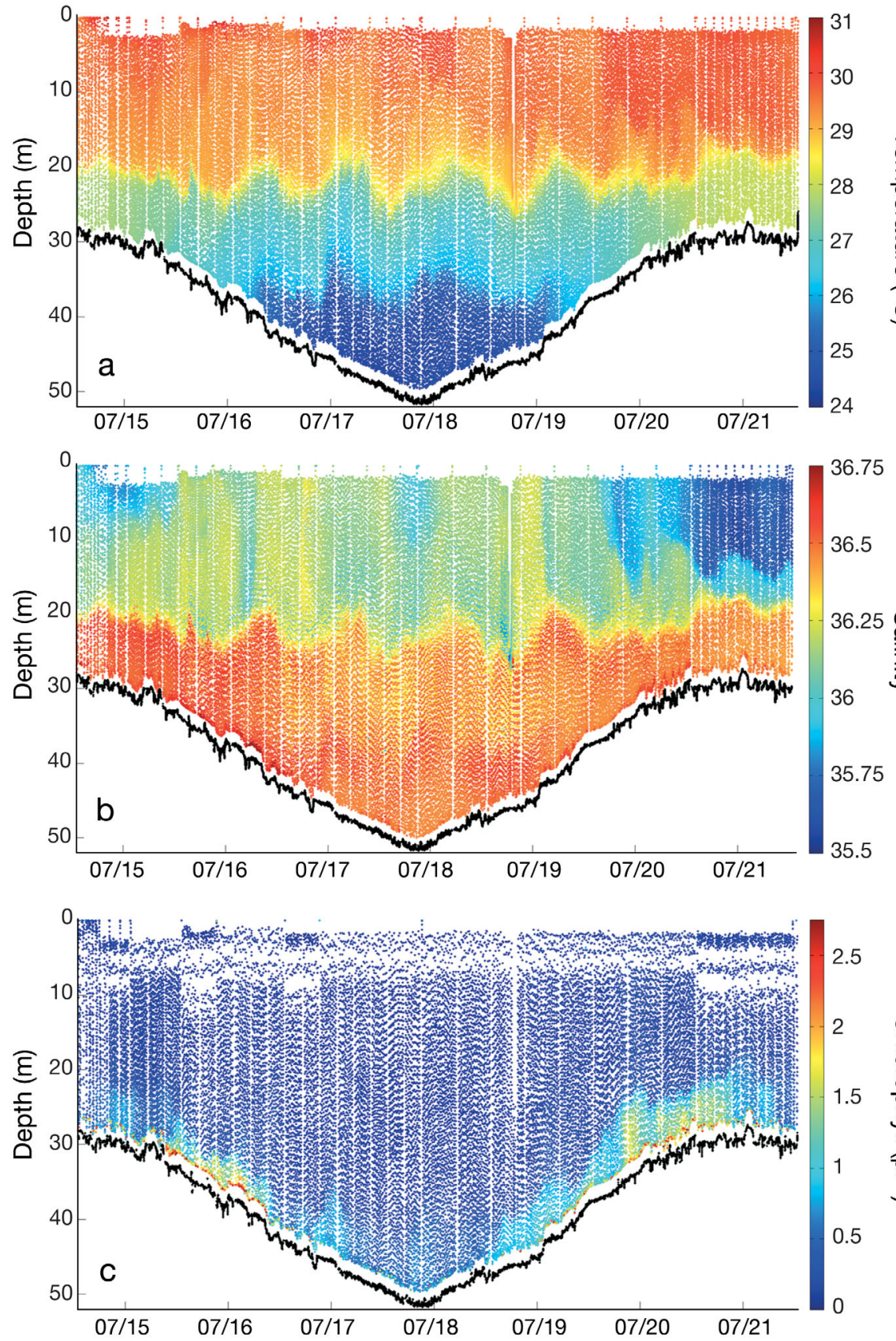

Fig. 9. Environmental data measured along the spatial track (date of recording, $\mathrm{mm} / \mathrm{dd}$ ) by sensors on the glider included (a) temperature $\left({ }^{\circ} \mathrm{C}\right)$, (b) salinity, and (c) chlorophyll $\left(\mu \mathrm{g} \mathrm{l}^{-1}\right)$. The black line indicates the bottom depth measured by the glider's altimeter

the aid of fixed acoustic arrays and a video observation system (Rountree 2008) to increase the chances of successful identification in future work.

The 3 environmental parameters shown (temperature, salinity, chlorophyll concentration) provide an initial glimpse into the environment in which the recorded sounds were produced. Stratification of the water column is attributed to the high heat flux and a lack of strong storms (>15 knot winds) in the area, which effectively mix density layers (He \& Weisberg 2002, Virmani \& Weisberg 2003). The fundamental frequency of some soniferous fish (including $O p$ sanus sp.) changes with temperature, making concurrent environmental data essential in understanding sound production (Fine 1978, Brantley \& Bass 1994, Connaughton et al. 2000). Furthermore, the link between sound production and spawning necessitates mapping temporal and spatial ranges of sound as a noninvasive proxy for identifying potential spawning habitat (Fine 1978, Brantley \& Bass 1994, Mann \& Lobel 1995, Lobel 2002, Locascio \& Mann 2008, Van Parijs et al. 2009, Rountree \& Juanes 2010, Nelson et al. 2011).

Glider technology provides a reliable and relatively inexpensive method to collect acoustic data in the field while maintaining a high rate of successful retrieval (Schofield et al. 2007). Moored PAM systems can be effective but have greater risk of being lost, stolen or damaged, especially in highly active areas (Luczkovich et al. 2008, Dudzinski et al. 2009). In addition, the spatial coverage and suite of environmental and optical conditions measured concurrently by the glider provide detail of the ocean environment and acoustic scene that cannot be discerned from stationary PAM methods that record only sound (Rudnick et al. 2004).

Remotely operated vehicles (ROV) have also been used as a platform for passive acoustic studies (Rountree \& Juanes 2010). This application, while taking advantage of video observation, was greatly limited by the selfgenerated noise of the ROV, which frequently masked suspected sound production (Rountree \& Juanes 2010). Although the glider does not have the ROV's capability to maintain a fixed position, the absence of a mechanical propulsion system allows the glider to produce significantly lower noise. To date, we do not know the extent, if any, in changes in 
fish behavior as a result of the glider presence. Based on the level of self-generated noise, we suspect the impact is likely less than that of an ROV but more than a stationary acoustic array (Stoner et al. 2008).

Red grouper are a large commercial and recreational fishery in the Gulf of Mexico. In 2008, approximately $68 \mathrm{t}$ of commercial landings and over 130000 recreationally caught red grouper were reported (SEDAR 2009). In addition, red grouper are established as 'ecological engineers' whose behavior provides structure and protection for other reef fish and invertebrates (Jones et al. 1994, Coleman \& Williams 2002). Sustaining red grouper populations is therefore important at both the species and ecosystem levels (Jones et al. 1994, Wright \& Jones 2006). However, the current methods used to assess and manage fisheries are limited by survey bias, inaccurate fisher reports and extensive delays between fisheries data collection and population assessment (NRC 2006). These limitations preclude real-time stock assessment and create a potentially harmful lag in accounting for the impact of overfishing and episodic environmental events such as red tides (SEDAR 2009). Additional methods that collect near real-time stock assessment data and use a no-take approach are needed to effectively manage species with greater immediacy, which will aid in maintaining long-term population stability and fishing activities. We suggest the implementation of regular deployments of hydrophone-integrated gliders as a possible method for enhancing fisheries management.

Acknowledgements. We thank the University of South Florida (USF), Center for Ocean Technology glider staff, namely M. Lindemuth, D. Edwards, A. Warren and A. Farmer. This research was funded by the National Oceanographic Partnership Program (NOPP) (OCE-0741705) awarded to D.A.M., the USF/US Geological Survey Graduate Assistantship awarded to C.C.W., and Office of Naval Research (N00014-04-1-0573 and N00014-10-1-0784) awarded to C.L. We also acknowledge the many helpful suggestions from the anonymous reviewers and editor that improved the manuscript.

\section{LITERATURE CITED}

Aristotle (1910) Historia animalium (translated by DA Thompson). The Internet Classics Archive. Accessed June 22, 2011. http://classics.mit.edu/Aristotle/history_ anim.6.vi.html

Bass A, Clark C (2003) The physical acoustics of underwater sound communication. In: Simmons AM, Fay RR, Popper AN (eds) Acoustic communication. Springer, New York, NY

Baumgartner MF, Fratantoni DM (2008) Diel periodicity in both sei whale vocalization rates and the vertical migra- tion of their copepod prey observed from ocean gliders. Limnol Oceanogr 53:2197-2209

Brantley RK, Bass AH (1994) Alternative male spawning tactics and acoustic signals in the plainfin midshipman fish Porichthys notatus Girard (Teleostei, Batrachoididae). Ethology 96:213-232

> Castelao R, Glenn S, Schofield O, Chant R, Wilkin J, Kohut J (2008) Seasonal evolution of hydrographic fields in the central Middle Atlantic Bight from glider observations. Geophys Res Lett 35:L03617. doi:10.1029/ 2007GL032335

> Coleman FC, Williams SL (2002) Overexploiting marine ecosystem engineers: potential consequences for biodiversity. Trends Ecol Evol 17:40-44

> Connaughton MA (2004) Sound generation in the searobin (Prionotus carolinus), a fish with alternate sonic muscle contraction. J Exp Biol 207:1643-1654

Connaughton MA, Taylor MH, Fine ML (2000) Effects of fish size and temperature on weakfish disturbance calls: implications for the mechanism of sound generation. J Exp Biol 203:1503-1512

Doksæter L, Godø OR, Handegard NO, Kvadsheim PH, Lam FPA, Donovan C, Miller PJO (2009) Behavioral responses of herring (Clupea harengus) to 1-2 and 6-7 kHz sonar signals and killer whale feeding sounds. J Acoust Soc Am 125:554-564

Dudzinski KM, Brown SJ, Lammers M, Lucke K and others (2009) Trouble-shooting deployment and recovery options for various stationary passive acoustic monitoring devices in both shallow- and deep-water applications. J Acoust Soc Am 129:436-448

Ferguson BG, Lo KW, Rodgers JD (2010) Sensing the underwater acoustic environment with a single hydrophone onboard an undersea glider. In: OCEANS 2010. IEEE, Sydney

Fine ML (1978) Seasonal and geographical variation of the mating call of the oyster toadfish Opsanus tau L. Oecologia 36:45-57

Fish MP, Mowbray WH (1970) Sounds of western north Atlantic fishes. Johns Hopkins Press, Baltimore, MD

Gannon DP (2008) Passive acoustic techniques in fisheries science: a review and prospectus. Trans Am Fish Soc 137:638-656

Gray, GA, Winn HE (1961) Reproductive ecology and sound production of the toadfish, Opsanus tau. Ecology 42: $274-282$

Haun J, Ryan K, Portunato N (2008) Marine mammal risk mitigation using passive acoustic technologies. In: New trends for environmental monitoring using passive systems. IEEE, Hyeres

Hawkins A (1993) Underwater sound and fish behaviour. In: Pitcher T (ed) Behaviour of teleost fishes, Book 2. Chapman \& Hall, London, p 129-169

He R, Weisberg RH (2002) West Florida shelf circulation and temperature budget for the 1999 spring transition. Cont Shelf Res 22:719-748

Hoese HD, Moore RH (1998) Fishes of the Gulf of Mexico, Texas, Louisiana, and adjacent waters. Texas A\&M University Press, College Station, TX

Jones C, Lawton J, Shachak M (1994) Organisms as ecosystem engineers. Oikos 69:373-386

Knudsen FR, Hawkins A, McAllen R, Sand O (2009) Diel interactions between sprat and mackerel in a marine lough and their effects upon acoustic measurements of fish abundance. Fish Res 100:140-147 
Lobel P (2002) Diversity of fish spawning sounds and the application of passive acoustic monitoring. Bioacoustics 12:286-288

Lobel PS, Kaatz IM, Rice AN (2010) Acoustical behavior of coral reef fishes. In: Cole KS (ed) Reproduction and sexuality in marine fishes: patterns and processes. University of California Press, Berkeley, CA, p 307-380

Locascio JV, Mann DA (2008) Diel periodicity of fish sound production in Charlotte Harbor, Florida. Trans Am Fish Soc 137:606-615

Luczkovich JJ, Mann DA, Rountree RA (2008) Passive acoustics as a tool in fisheries science. Trans Am Fish Soc 137:533-541

Mann DA, Grothues T (2008) Short-term upwelling events modulate fish sound production at a mid-Atlantic Ocean observatory. Mar Ecol Prog Ser 375:65-71

Mann DA, Lobel PS (1995) Passive acoustic detection of sounds produced by the damselfish, Dascyllus albisella (Pomacentridae). Bioacoustics 6:199-213

Matsumoto H, Haxel JH, Dziak RP, Bohnenstiehl DR, Embley RW (2011) Mapping the sound field of an erupting submarine volcano using an acoustic glider. J Acoust Soc Am 129:EL94-EL99

Mellinger DK, Stafford KM, Moore S, Dziak RP, Matsumoto $\mathrm{H}$ (2007) Fixed passive acoustic observation methods for cetaceans. Oceanography (Wash DC) 20:36-45

Moore SE, Howe BM, Stafford KM, Boyd ML (2007) Including whale call detection in standard ocean measurements: application of acoustic seagliders. Mar Technol Soc J 41:53-57

Nelson MD, Koenig CC, Coleman FC, Mann DA (2011) Sound production of red grouper Epinephelus morio on the West Florida Shelf. Aquat Biol 12:97-108

Nøttestad L (1998) Extensive gas bubble release in Norwegian spring-spawning herring (Clupea harengus) during predator avoidance. ICES J Mar Sci 55:1133-1140

NRC (National Research Council) (2006) Review of recreational fisheries survey methods. National Academies Press, Washington, DC

Rountree RA (2008) Do you hear what I hear? Future technological development-and needs-in passive acoustics underwater observation. Mar Technol Rep 51:40-46

Rountree RA, Juanes F (2010) First attempt to use a remotely operated vehicle to observe soniferous fish behavior in the Gulf of Maine, Western Atlantic Ocean. Curr Zool 56: 90-99

Rountree RA, Gilmore RG, Goudey CA, Hawkins AD, Luczkovich JJ, Mann DA (2006) Listening to fish: appli-

Editorial responsibility: Peter Corkeron, Woods Hole, Massachusetts, USA cations of passive acoustics to fisheries science. Fisheries 31:433-446

Rudnick DL, Davis RE, Eriksen CC, Fratantoni DM, Perry MJ (2004) Underwater gliders for ocean research. Mar Technol Soc J 38:73-84

Schofield O, Kohut J, Aragon D, Creed L and others (2007) Slocum gliders: robust and ready. J Field Robot 24: 473-485

SEDAR Southeast Data Assessment and Review (2009) Stock assessment of red grouper in the Gulf of Mexico. In: Atran S, O'Hern T, Neer J (eds) Report of Assessment Workshop, Miami, FL

- Stoner AW, Ryer CH, Parker SJ, Auster PJ, Wakefield WW (2008) Evaluating the role of fish behavior in surveys conducted with underwater vehicles. Can J Fish Aquat Sci 65:1230-1243

Tavolga WN (1958) Underwater sounds produced by two species of toadfish, Opsanus tau and Opsanus beta. Bull Mar Sci 8:278-284

> Thorson RF, Fine ML (2002) Crepuscular changes in emission rate and parameters of the boatwhistle advertisement call of the gulf toadfish, Opsanus beta. Environ Biol Fishes 63:321-331

Urick R (1983) Principles of underwater sound, Vol 1. McGraw-Hill, New York

> Van Parijs SM, Clark CW, Sousa-Lima RS, Parks SE, Rankin S, Risch D, Van Opzeeland IC (2009) Management and research applications of real-time and archival passive acoustic sensors over varying temporal and spatial scales. Mar Ecol Prog Ser 395:21-36

Virmani JI, Weisberg RH (2003) Features of the observed annual ocean-atmosphere flux variability on the west Florida shelf. J Clim 16:734-745

Wahlberg M, Westerberg H (2003) Sounds produced by herring (Clupea harengus) bubble release. Aquat Living Resour 16:271-275

> Webb DC, Simonetti PJ, Jones CP (2001) SLOCUM: an underwater glider propelled by environmental energy. IEEE J Oceanic Eng 26:447-452

Wilson B, Batty RS, Dill LM (2004) Pacific and Atlantic herring produce burst pulse sounds. P Roy Soc Lond B Bio 271:S95-S97

Winn H (1964) The biological significance of fish sounds. In: Tavolga WN (ed) Marine bio-acoustics. Pergamon Press, New York, NY

- Wright J, Jones C (2006) The concept of organisms as ecosystem engineers ten years on: progress, limitations, and challenges. Bioscience 56:203-209

Submitted: August 4, 2011; Accepted: December 9, 2011 Proofs received from author(s): February 16, 2012 